\title{
Béla Szilágyi
}

\section{Refugee Camp: A Tool for Dignity and Security ${ }^{1}$}

\begin{abstract}
Migration is the main challenge of the $21^{\text {st }}$ century. With 272 million people migrating in 2019, of whom 80 million people are forcibly displaced worldwide, their security and the security of those living in the destination countries or regions is a major concern. One of the decisive factors in protection and security is the planning and management of the camps where millions of refugees and internally displaced people are hosted, in several cases, for many years. Well planned and well-organized camps do not only provide assistance and ensure the dignity to those displaced, help the effective work of the aid workers, but can also contribute to reducing crime and gender-based violence, furthermore decrease security threats and concerns. This paper examines how migrant settlement options, especially camps can be a tool for upholding the dignity of those in the camp whether they are refugees, internally displaced persons or different kinds of migrants, but at the same time how they can provide the safety and security for both the hosted population and the hosting community. For this very reason, the purpose of a shelter, the advantages and disadvantages of camps, furthermore setting and planning of camps will be discussed.
\end{abstract}

Keywords: refugee camps, camp management, dignity, security, protection, migration

\section{Introduction}

People have been involved in migration, 'the movement of persons away from their place of usual residence, either across an international border or within a State' (International Organization for Migration IOM, 2019a), since our world

1 My research is connected to the protection of critical infrastructure. My results were presented at the ICCECIP 2020 Conference and its written summary is published in this article. 
has been populated. Voluntary migration to find better living conditions, and involuntary migration driven by hostilities or disasters, are as old as humanity. Euripides writes in his play Medea in $431 \mathrm{BC}$ : 'There is no greater sorrow on Earth, than the loss of one's native land' (URL1). It is a constantly growing phenomenon, the estimated number of international migrants were 84 million in 1970, it grew to 153 million in twenty years by 1990, while it reached 272 million in 2019 (IOM, 2019b).

Forced migration is a non-voluntary or involuntary migratory movement which, although the drivers can be diverse, involves force, compulsion, or coercion. The term has been used to describe the movements of refugees, displaced persons (including those displaced by disasters or development projects), and victims of trafficking. In other terms, forced migration is an involuntary migratory movement of people who wish to escape an armed conflict, violence, the violation of their rights or a disaster (IOM, 2019a). The 1951 Convention Relating to the Status of Refugees provides the definition of refugee in Article 1 as any person who 'owing to well-founded fear of being persecuted for reasons of race, religion, nationality, membership of a particular social group or political opinion, is outside the country of his nationality and is unable or, owing to such fear, is unwilling to avail himself of the protection of that country; or who, not having a nationality and being outside the country of his former habitual residence as a result of such events, is unable or, owing to such fear, is unwilling to return to it' (UNHCR, 2010). The term, internally displaced persons is not defined in a legally binding convention or treaty. The United Nations accepted the report E/CN.4/1998/53/Add.2 with the addendum, Guiding Principles on Internal Displacement, presented to the Commission on Human Rights by Representative of the Secretary General on internally displaced persons Francis M. Deng in 1998. The principles, although not binding, have been widely used and complied with since then. According to the Guiding Principles on Internal Displacement, IDPs are 'persons or groups of persons who have been forced or obliged to flee or to leave their homes or places of habitual residence, in particular as a result of or in order to avoid the effects of armed conflict, situations of generalized violence, violations of human rights or natural or human-made disasters, and who have not crossed an internationally recognized state border' (United Nations Economic and Social Council, 1998). This definition fits exactly with the Sahrawis displaced from Western Sahara, who were forced to leave their homeland in 1975 and have since then plagued more than 150,000 in refugee camps in Algeria (Besenyő, 2010).

The 2015 migration wave in Europe qualifies as a migration crisis by the IOM definition of 'a complex and often large-scale migration flows and mobility 
patterns caused by a crisis which typically involve significant vulnerabilities for individuals and affected communities and generate acute and longer-term migration management challenges' (IOM, 2019a).

Although Europe has always been a destination region for voluntary and involuntary migrants, the 2015 migration wave produced an influx in a short time, not seen in Europe before. In comparison, even in 1992, after the collapse of the Soviet Union and the fall of the Iron Curtain, 697,000 people applied for asylum to the nations that make up the EU now. In 2002, due to the Kosovo crisis, 463,000 asylum applications were received (Connor, 2016).

As part of the 2015 migration wave, over 1.3 million people applied for asylum in the 28 European Union countries, Norway and Switzerland, vast majority of them are from three countries: Syria, Afghanistan and Iraq. While unquestionably Germany was the primary target / destination country with 442,000 asylum applications in 2015, followed by Hungary (174,000 applications) and Sweden $(156,000)$, Hungary received the most $(1,770)$ first time asylum-applications per 100,000 of the country's population, just ahead of Sweden $(1,600)$, but far more than Austria (1,000), Norway (590), Finland (590) and Germany (540) (Connor, 2016).

Complex underlying reasons drove this migration wave, with a wide range of push factors driving people to leave their country, especially Syria and Iraq: the unstable political systems of origin countries; the hostilities, terrorist attacks, human rights violations and persecution by governments, the Islamic State of Iraq and Syria (ISIS) and other organizations; the declining economic and employment opportunities; the scarce water resources and agricultural opportunities. The pull factors attracting them into the country of destination were manifold, as well: expectation of safety; shortage of work force in Western Europe and open economic opportunities; promises made by some politicians of the destination countries; and the coercion of smugglers.

There is an ongoing fierce debate what percentage of the migrants in the European migration wave in 2015 and forward were voluntary migrants, 'economic migrants', trying to find better living standards and work opportunities, or involuntary or forced migrants who had to leave their home country because of persecution, hostilities and terrorist attacks. The term 'economic migrant' is not a category in international law, it is used to refer to people on the move solely or primarily motivated by economic opportunities (IOM, 2019a). The European migration wave may be considered a mixed movement (mixed migration) where people are travelling together, generally in an irregular manner, using the same routes and means of transport, but for different reasons. They have varying needs and profiles and may include asylum seekers, refugees, trafficked 
persons, unaccompanied/separated children, and other migrants [including economic migrants] in an irregular situation (IOM, 2019a).

The number of forced migrants reached almost 80 million worldwide, this equals to the population of Germany. The 45.7 million people are internally displaced, the largest IDP group is the 6 million Syrians. The number of 26 million refugees includes 5.4 Palestinians under UNRWA ${ }^{2}$ mandate. 73 per cent of refugees lived in neighbouring countries, while developing countries hosted 85 per cent of the world's refugees and Venezuelans displaced abroad (UNHCR, $2020 \mathrm{c}$ ). Of the 20.4 million refugees under $\mathrm{UNHCR}^{3}$ mandate, more than half comes from three countries: 6.6 million from Syria, 2.7 million from Afghanistan and 2.2 million from South Sudan (UNHCR, 2020b).

Figure 1: Number of forcibly displaced people in 2019

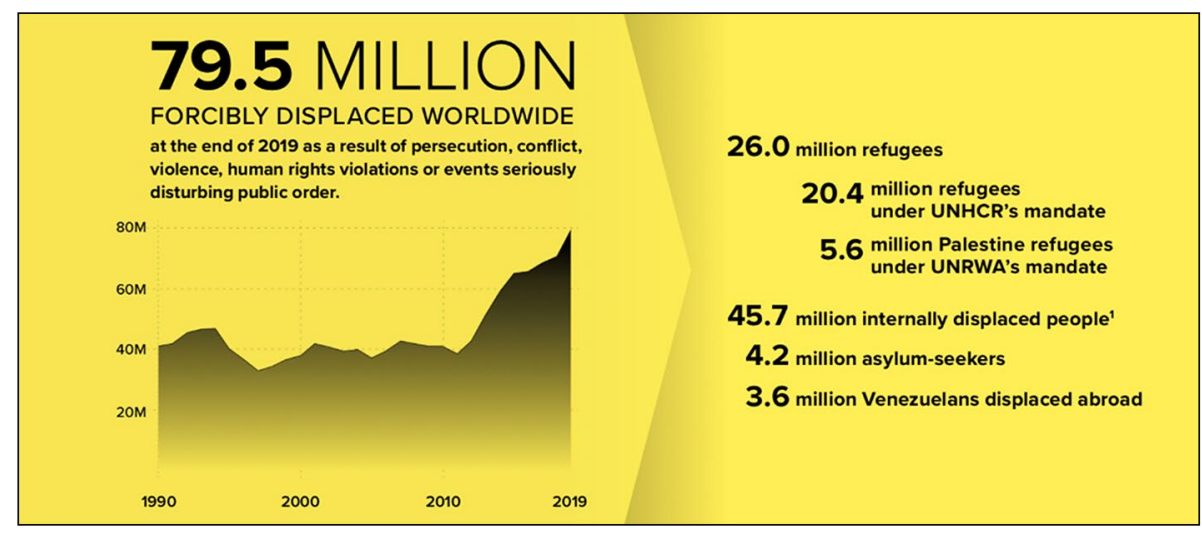

Note: UNHCR: Global Trends Forced Displacement in 2019.

In just two short years, from 2017 to 2019 the number of forcibly displaced people worldwide rose by 11 million (just in comparison: this is more than the population of Hungary) mainly due to the increase of IDPs and the occurrence of Venezuelans displaced abroad. The 79.5 million forcibly displaced represent a close to $100 \%$ increase in just a short decade from 41.1 million in 2010 (UNHCR, 2020c).

2 United Nations Relief and Works Agency for Palestine Refugees in the Near East (UNRWA).

3 United Nations High Commissioner for Refugees (UNHCR). The organization now refers to itself as UNHRC The UN Refugee Agency. 
Figure 2: Number of forcibly displaced people in 2017

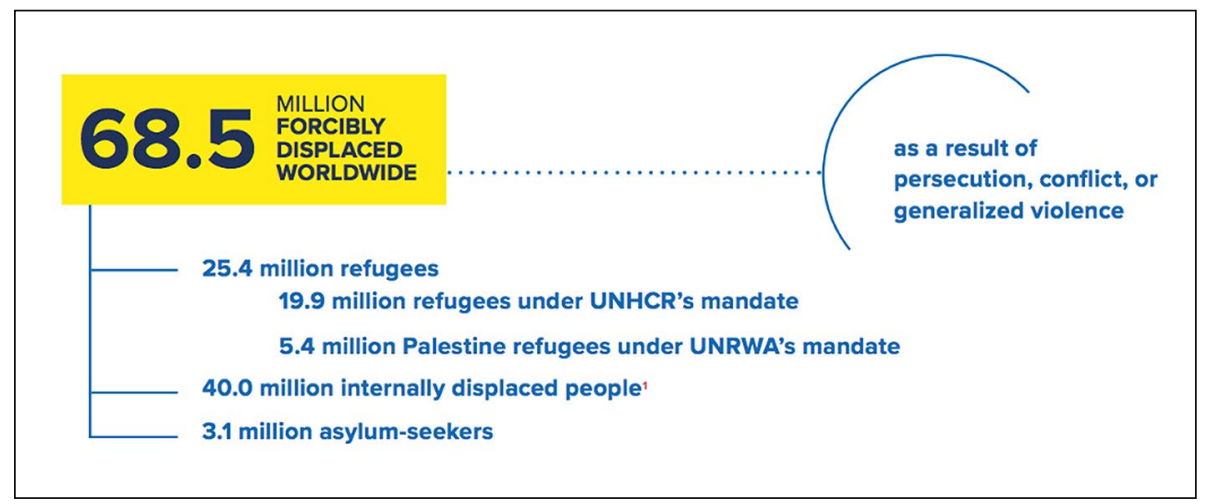

Note: UNHCR: Global Trends Forced Displacement in 2017.

\section{Shelter Assistance Solutions, Shelter Categories and Settlement Options}

The six settlement options for displaced populations include host families, urban and rural self-settlements, collective centres settlements, self-settled and planned camps. These are categorized into three categories of shelters: local dispersion, mass dispersion and camps. In local dispersion they are put up by host families or they occupy uninhabited buildings, self-scatter in urban or rural areas, unaffected land, even forests. In mass dispersion, migrants are hosted in large public infrastructure, like schools, gymnasiums, stadiums, auditoriums, warehouses. Camps, whether self-settled or planned, are the ultimate solution. Host families, urban and rural self-settlements are less visible, and migrants in these local dispersion options are more difficult to access, to be supported and protected, more vulnerable, but at the same time the host communities are also less protected from possible perpetrators.

UNHCR highlights some of the issues of the local dispersion and mass dispersion in city or urban areas, where 'many refugees share accommodation or live in non-functional public buildings, collective centres, slums and informal types of settlements. Conditions are often substandard and providing shelter poses major challenges' (URL2). 
Figure 3: The Six Settlement Options for Displaced Populations and the Three Shelter Categories

\begin{tabular}{|l|l|l|}
\hline \begin{tabular}{|l|l|}
\hline Host families \\
Local families shelter the displaced population within their \\
households or on their properties.
\end{tabular} \\
$\begin{array}{l}\text { Urban self-settlement } \\
\text { Unclaimed urban properties, or land unaffected by the } \\
\text { disaster, are used informally by displaced populations. }\end{array}$ & Local Dispersion \\
$\begin{array}{l}\text { Rural self-settlement } \\
\text { Displaced populations create a settlement on collectively } \\
\text { owned rural land. }\end{array}$ & $\begin{array}{l}\text { Collective centres settlement } \\
\text { Existing large structures, such as schools, can serve as } \\
\text { collective shelters. }\end{array}$ & Mass Dispersion \\
\hline $\begin{array}{l}\text { Self-settled camps } \\
\text { Independent from government or int'I organisation } \\
\text { support, camps are formed by the displaced population. }\end{array}$ & Camps \\
\hline $\begin{array}{l}\text { Planned camps } \\
\text { Government or aid organisations plan camps, including } \\
\text { infrastructure, to house displaced populations. }\end{array}$ & \\
\hline
\end{tabular}

Note: Created by the author, based on United Nations Office for the Coordination of Humanitarian Affairs et al.: Shelter after Disaster.

The following few pictures shows how migrants are settled in the most visible options, mass dispersions and camps. The first picture shows IDPs in the USA in mass dispersion, who lost their homes due to Tropical Storm Harvey in 2017 and settled in George R. Brown Convention Center in Houston, Texas. A more recent picture is another example of mass dispersion from the Philippines after the Taal Volcano eruption in 2020. IDPs are hosted in tents set up in the warehouse of the Old Tanauan City Hall. In Haiti, most of the earthquake affected population settled either in urban self-settlement or, in a more significant number, in self-settled or ad-hoc camps. Turkey set up very well planned and well-organized camps for the Syrian and Iraqi refugees. 
Figure 4: Mass Dispersion. George R. Brown Convention Center in Houston, Texas

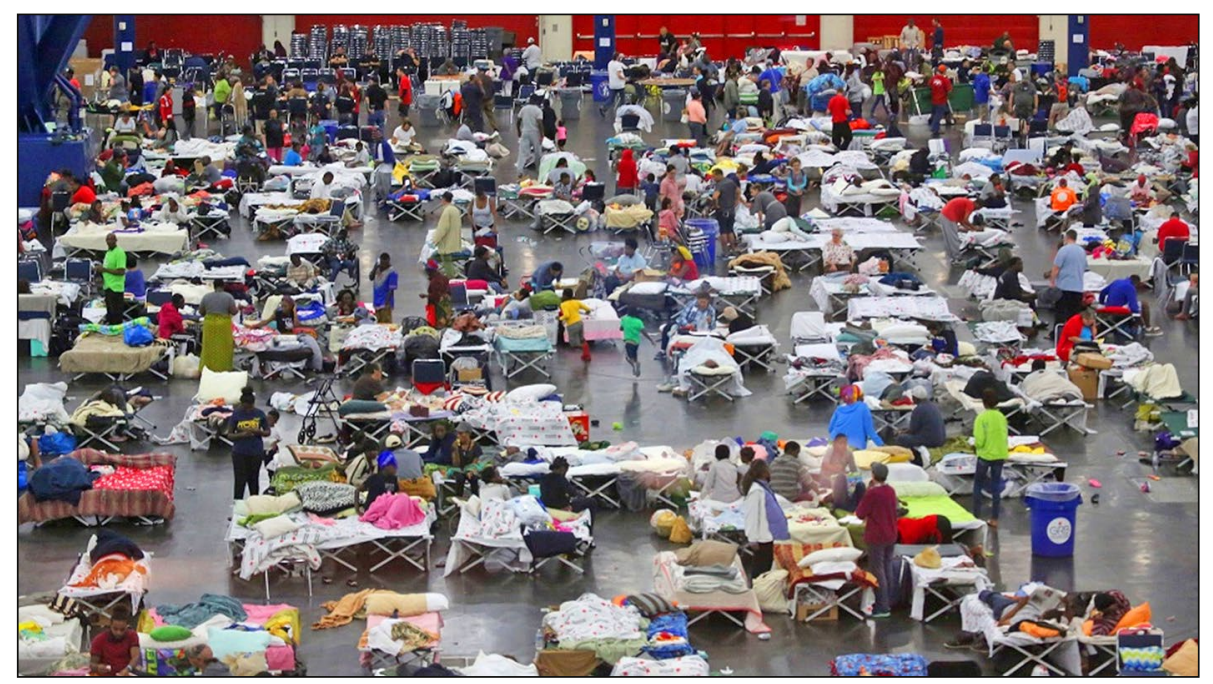

Note: Lagerquist, Jeff: 'Soaked': Harvey’s victims find relief inside Houston's largest evacuation centre (URL3).

Figure 5: Mass Dispersion. Old Tanauan City Hall, Philippines

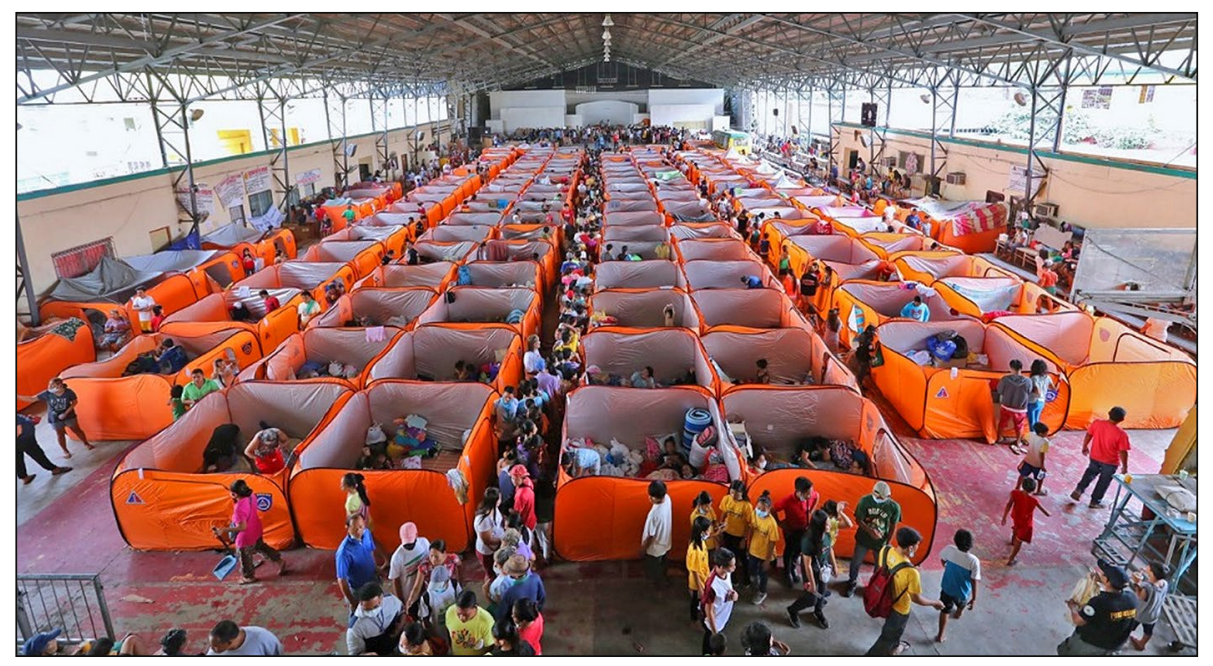

Note: Razon, Joseph: Evac Center (URL4). 
Figure 6: Self-settled Camp. IDPs in front of the Presidential Palace, Port-au-Prince, Haiti

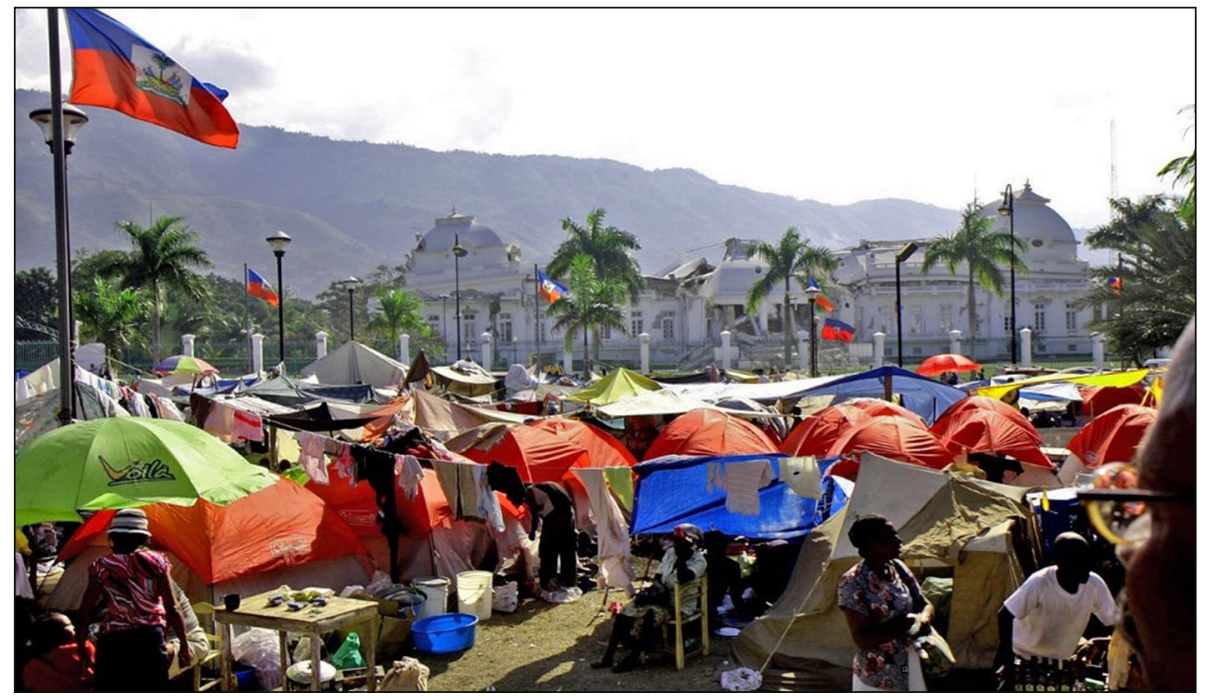

Note: Created by the author.

Opened in February 2015 and run by the Disaster and Emergency Management Presidency (AFAD), the Suruç camp hosted up to 35,000 refugees. It was the biggest refugee city in Turkey with the essential facilities e.g., four schools, a health centre, a firefighting unit, playgrounds, psychosocial support areas, television tents, prayer rooms, playgrounds, sports areas, markets (URL5).

Figure 7: Well-Planned Camp. Suruç, Turkey

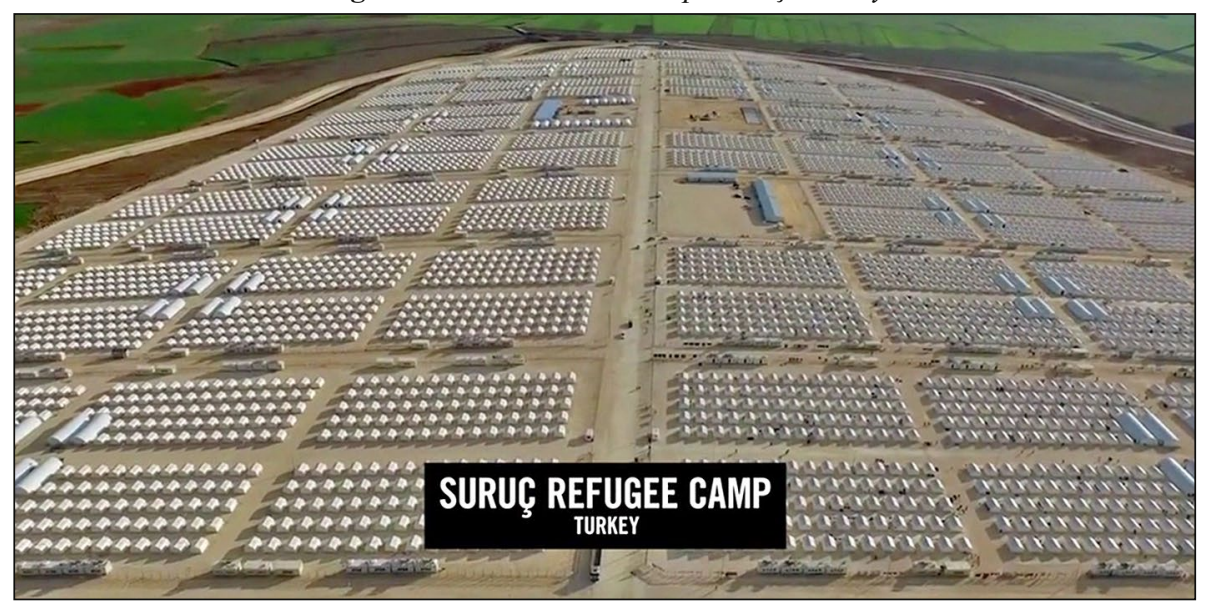

Note: Lim, Wyatt Mingji: The Turkish Pivot (URL5). 
The Humanitarian Reform Agenda introduced the Cluster Approach in place of the previously used sectors in 2005. Clusters are groups of UN and non-UN humanitarian organizations in the main segments or sectors of humanitarian action (URL6). The Inter-Agency Standing Committee (IASC, 2015) designated 11 clusters $^{4}$ to strengthen system-wide preparedness and technical capacity to respond to humanitarian emergencies and provide clear leadership and accountability in the main areas of humanitarian response. The Global Shelter Cluster (GSC, 2010) is co-chaired by the International Federation of Red Cross and Red Crescent Societies (IFRC) and UNHCR. IFRC is convener in natural disasters while UNHCR leads in conflict situations. The Global Camp Coordination and Camp Management (CCCM) Cluster is to coordinate humanitarian actors with services to displaced populations; the lead agency is IOM in disaster settings and UNHCR in conflict situations, complex emergencies (URL6).

Camps are sometimes the only option and may be the last resort to host displaced persons (IOM, NRC \& UNHCR, 2015). Camps are not the permanent sustainable solution; they may only offer temporary provision of protection and assistance with the aim to uphold the basic rights for the displaced. Residence in a camp is never to be considered as a durable solution, it is a temporary response to a situation of displacement. For IDPs and refugees, achievement of a durable solution (repatriation/return, local integration or resettlement) is the key to ending displacement. The Camp Management House illustrates the holistic approach and a cross-cutting sector response of camp management, which is both technical and social in its aims (IOM, NRC \& UNHCR, 2015).

Figure 8: The Camp Management House

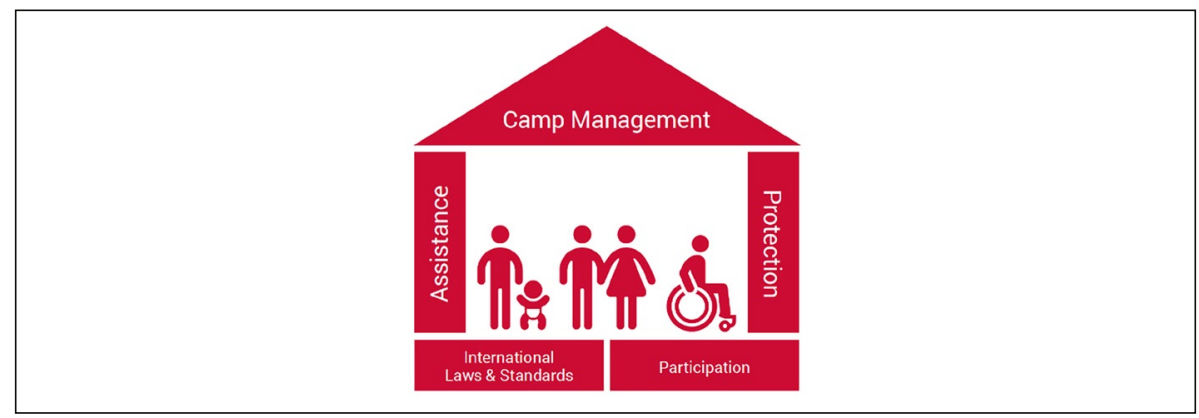

Note: IOM, NRC \& UNHCR: Camp Management Toolkit.

4 Global Camp Coordination and Camp Management (CCCM) Cluster, Global Cluster for Early Recovery (GCER), Education Cluster, Emergency Telecommunications Cluster (ETC), Food Security Cluster (FSC), Global Health Cluster, Logistics Cluster, Global Nutrition Cluster (GNC), Global Protection Cluster, Global Shelter Cluster (GSC) and Global Water Sanitation and Hygiene WASH Cluster (GWC) (URL6). 


\section{Shelters}

According to UNHCR data, more than 6.6 million refugees and people in refuge-like situations live in camps, among them 4.6 million in planned/managed camps and about 2 million in self-settled camps (URL2).

What migrants / refugees / IDPs are looking for in a shelter, in camps or other settlement options?

Shelter is defined as 'a habitable covered living space, providing a secure, healthy living environment with privacy and dignity to the groups, families, and individuals residing within it' (Corsellis, 2005).

The most important priority for displaced people in a shelter is physical and psychological protection. They want protection from weather and the elements, security from violence, attacks and crime, and a safe place for their family life. They search for dignity and private space. They look for healthy living conditions, access to water, hygiene, livelihood and possible work activities.

Figure 9: What does a shelter provide?

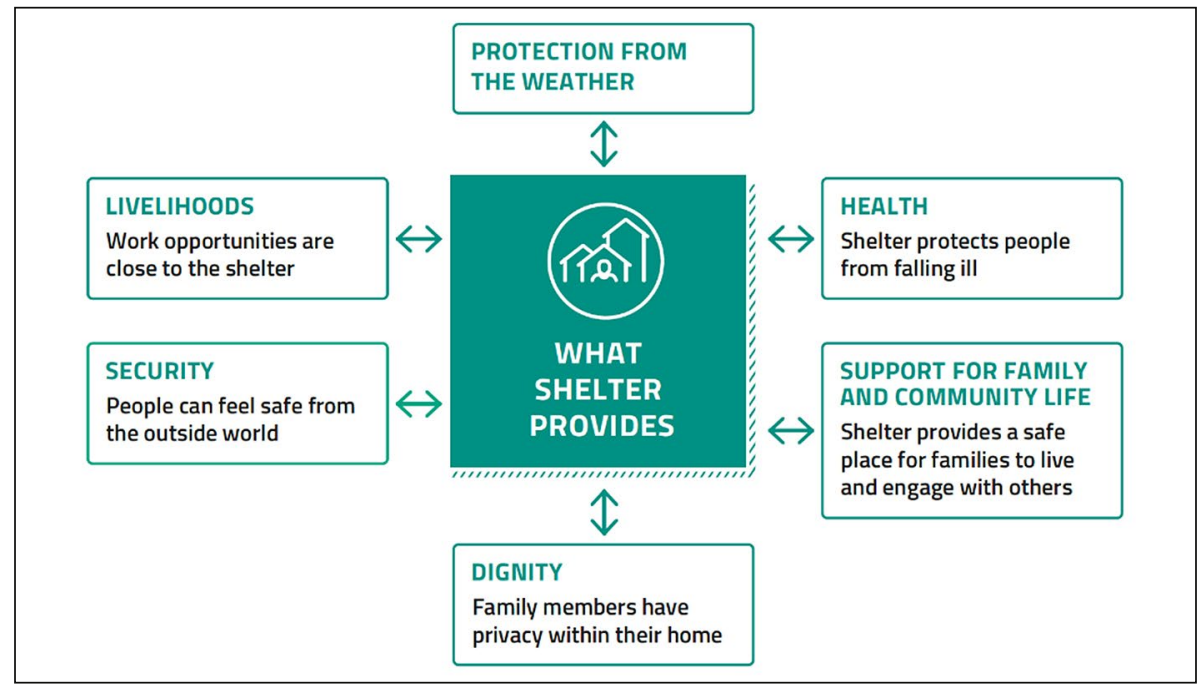

Note: Sphere Association: Sphere Handbook.

In a camp situation, the minimum standards for a shelter, as set out by both Sphere and UNHCR, is 3.5 square metres of living space per person, excluding cooking, bathing and sanitation spaces (Sphere Association, 2018; UNHCR, 2007). This means 25 square meters for a family of six, which is an extremely small space, but most times this is what needs to be dealt with. The living 
space per person should be 4.5-5.5 square metres in cold climates or urban settings (including cooking, bathing and sanitation spaces). The internal floorto-ceiling height is expected to be lower in cold climate: at least 2 metres, but higher, 2.6 metres in hot climates (Sphere Association, 2018). The minimum surface area is 45 square metres per person in camp-type settlements, including household plots. The 45 square metres per person includes firebreaks, roads and footpaths, personal or communal cooking areas, sanitation facilities, healthcare facilities, administrative and educational buildings, warehouses, markets, water storage, drainage, food distribution sites, religious and recreational facilities, and kitchen gardens for individual households, but does not include agricultural activities or livestock. The minimum surface area is 30 square metres per person if communal services can be provided outside of the camp (Sphere Association, 2018).

Beyond the shelters, non-food items need to be provided for those living in the camps. Non-food items include minimum

- two full sets of sufficient quality clothing per person, in the right size and appropriate to culture, season and climate, and adapted to particular needs;

- one sufficient and appropriate quality blanket and bedding (floor mat, mattress, sheeting) per person, for safe, healthy and private sleeping;

- additional blankets/ground insulation required in cold climates;

- long-lasting insecticide-treated nets;

- two family-sized cooking pots with handles and lids, one basin for food preparation or serving, one kitchen knife and two serving spoons per household or group of four to five individuals to prepare, eat and store food;

- one dished plate, one set of eating utensils and one drinking vessel per person;

- sufficient, safe and affordable energy supply to maintain thermal comfort, prepare food and provide lighting (Sphere Association, 2018).

Even if for the shortest time possible, the shelter becomes a home. However, by 2003 the average time of a refugee crisis increased to 17 years (UNHCR, 2004). 'Average length of stay in a \#refugee camp once it passes 5 years gets up to around 20 yrs now,' tweeted the UNHCR United States (URL7). The largest refugee camp in the world, Kenya's Dadaab built for 90,000 refugees in 1991, turns 30 years old in 2021. It held more than 420,000 refugees and asylum seekers in 2014 (URL8; URL9; URL10), while 218,873 registered refugees and asylum seekers lived here at the end of July 2020 (URL11). A protracted refugee situation, as defined by UNHCR, is where '25,000 or more refugees from the same nationality have been in exile for five consecutive years or more' in a 
given host country ${ }^{5}$. More than three quarters of all refugees, 15.9 million refugees were in protracted situations at the end of 2018. More than one quarter, 5.8 million were in a situation lasting 20 years or more, 2.4 million of them are Afghan refugees in Iran and Pakistan for 40 years. Additional situations over 40 years are the refugees from Western Sahara in Algeria, from Burundi in Tanzania and from Vietnam in China. Certainly, it does not mean that individuals have necessarily been displaced for 40 years, since births and deaths, departures and new arrivals took place. Half of the refugees were in protracted situations lasting 5 to 20 years, 6 million of them are displaced Syrians (UNHCR, 2019).

\section{Issues to Solve in order to Uphold Dignity and Ensure Security}

Beyond technical standards, the solution to several issues must drive the planning and organizational work of the camp in order to uphold the dignity of the beneficiaries while ensuring the security of those hosted and those hosting.

- Break-up of family, social and cultural networks

- Lack or low quality of education

- Poor nutritional status

- Poor general health conditions, more vulnerable to infections, viruses

- Poor access to services

- Generally, $75 \%$ of refugees/IDPs are women, girls and boys - though in the 2015 European migration wave, the percentage of singles was higher

- Many subjected to sexual and gender-based violence abuses

- More likely to be trafficked or smuggled

- Lack or unreliable identity documents

- Protection and security inside and outside of the camp

\section{Camp Planning}

In most rapid-onset situations, displaced populations arrive to a possible settlement area before humanitarian workers, and set up their dispersed settlement or self-settled, ad-hoc camps. However, if the displacement can be foreseen and expected, emphasis needs to be placed on planning the camp in advance.

One must not forget, if the camp is not planned, or a certain facility or service is not planned and set up in advance, the beneficiaries will do it, and chances are that the placement will not be ideal and easily manageable.

5 It does not include Palestinians under UNRWA mandate. 
Self-settled camps are more difficult to work with, beneficiaries are more difficult to be served, protected, and supported, services are more difficult to be set up and safely delivered in ad-hoc situations. Self-settled camps in addition pose more significant risks to the dignity, well-being and the security of the beneficiaries and the host communities. Beneficiaries are more difficult to identify and communicate with if they are not in the camp or not in a well-organized camp. Beneficiaries may be more vulnerable and durable solutions will be more difficult to be organized.

Planning the camp and making it a tool for dignity and security for both those in the camp and the outside host community.

The design of the settlement can contribute to reducing crime and gender-based violence, discusses the Sphere Handbook (Sphere Association, 2018). Consider the location and accessibility of shelters, buildings and facilities, night lighting, distance to the toilet and bathing area from the shelter, and passive surveillance through visual lines. Buildings used as collective centres must have alternative escape routes (Sphere Association, 2018). A well-designed camp protects the environment, disease outbreak and fires are prevented. Food, water, medical care and other services are in a walking distance for the displaced population. In order not to expose girls and women to danger, water points and latrines must be well-lit and close to homes (URL2).

Camps hosting over 20,000 should be avoided, however many times it is not possible. The following set up is planned for a population of 20,000.

- Roads and firebreaks $2 \mathrm{~m}$ between shelters, $7 \mathrm{~m}$ back from road

- Water supply, waterpoints, latrines, showers, refuse/garbage containers, water drainage

- Health facilities, clinics, hospital, pharmacy

- Feeding, nutritional feeding facilities

- Warehouse and distribution sites (food, non-food items)

- Administrative areas, reception centres, specialised services

- Market, schools, meeting places, cemeteries, religious centres

- The Shelters

\section{Services in the Camps in orderto Uphold Dignity and Ensure Security}

The health status of a camp population is often fragile and the beneficiaries are exposed to a complex threats and risk factors for disease and death. The main goals of health services in a camp situation are reducing mortality (loss of life), 
morbidity (illness) and disability, thus contributing to an improved quality of life. Measles is one of the most serious health problems encountered in a camp situation and is a leading cause of death in many refugee/IDP emergencies. Mass measles immunization campaign is a top priority. Prevention of diarrhoea and cholera outbreaks through hygiene promotion and access to safe water is inevitable. Acute malnutrition is a major cause of mortality in camp populations. Nutrition assessment and implementation of needs-based feeding programmes are important initial activities because malnutrition increases vulnerability to diseases. Adequate shelter, food and water supplies, vector control and proper excreta disposal, decreasing overcrowding, in addition to health education and training on key messages all contribute not only to the improvement of the environment and living conditions of the camp population upholding their dignity, but even more importantly, they are vital for the safety, health and well-being of those living in the camp (IOM, NRC \& UNHCR, 2015).

Food rations are usually based on the minimum calory intake of 2,100 kilocalories per person per day. An average adult needs 560 grams of food per day. Pregnant women will need an additional $300 \mathrm{kcal}$ per day in balanced diet, a breastfeeding woman will need an additional $500 \mathrm{kcal}$ per day. The healthy diet contains the following basic food items such as:

- cereals: fortified wheat flour, maize meal, bulgur wheat, sorghum or rice (420 grams/day/person),

- pulses/legumes: dried lentils, chickpeas or beans (50 grams/day/person),

- fats: cooking oil (fortified with vitamin A and D) (25 grams/day/person),

- fortified salt (5 grams/day/person),

- sugar,

- fortified blended food (Corn and Soya Blend (CSB),

- additionally,

- canned meat and/or fish,

- fresh fruit and vegetables,

- micro-nutrients (including vitamins and minerals) may also be provided (IOM, NRC \& UNHCR, 2015).

Calculated for a camp population of 20,000 people, this will mean 11.2 metric tons of food daily, 78.4 metric tons weekly and 336 metric tons monthly (IOM, NRC \& UNHCR, 2015)!

Diarrhoeal diseases are responsible for 40 per cent of mortality in the first phases of an emergency. Providing Water, Sanitation and Hygiene (WASH) services in sufficient quantity and quality is urgent for people to survive, stay in good health, and maintain dignity, WASH services are among the most vital 
and very first services provided in a camp (IOM, NRC \& UNHCR, 2015). Sphere requires one water tap for maximum 250 people (Sphere Association, 2018), while UNHCR sets one water tap per community (80-100 people) (UNHCR, 2007). The absolute minimum of 7 litres ${ }^{6}$ of water per day per person must be provided, but this needs to be increased to 20 litres per day per person as soon as possible, water standards for health centres: 40-60 litres per patient per day, feeding centres: 20-30 litres per patient per day, and schools: 3 litres/pupil/day (UNHCR, 2007). According to Sphere, the distance to the nearest waterpoint from households must be less than 500 metres, with shorter than 30 minutes of queuing time at water sources (Sphere Association, 2018). UNHCR sets these standards at no further than 200 metres or a few minutes' walk from water distribution points (UNHCR, 2007). The minimum standards for the services and facilities regulate one latrine per family (6 people) (UNHCR, 2007), but not more than 20 people, and one bathing facility per 50 people (Sphere Association, 2018). Likely water resources available to a camp are surface water such as from rivers, streams and lakes that might be contaminated and require treatment; groundwater such as from wells, boreholes or springs that is susceptible to contamination if not protected, and may or may not require treatment; municipal or private systems, which are likely to be treated and of good quality; rainwater will vary seasonally but may be invaluable, although rainwater is pure and clean in theory, collection and storage methods invariably compromise quality. If water is not locally available it may be supplied by water trucking, airlifting by plane or helicopter or desalination (diesel-electric/solar) (IOM, NRC \& UNHCR, 2015). Calculating by the Sphere's indicator of 15 litres of water per person per day, a camp of 20,000 people needs 0.3 million of litres a day, 109.5 million of litres a year only for personal use! (IOM, NRC \& UNHCR, 2015).

Education is an essential component of a holistic humanitarian response. Quality education saves lives by providing physical protection from dangers and exploitation often present during displacement. Education transmit life-saving information to children and their families; it strengthens survival skills and coping mechanisms essential during displacement. It mitigates the psychosocial impact of conflict, disaster and displacement. Going to school, and participating in learning with friends and trusted adults help children and their families regain a sense of routine, stability and structure in a chaotic and disorientating setting. For these very reasons, the choice of location for the learning spaces

6 In the $4^{\text {th }}$ Edition of Sphere Handbook (2018) it has been increased to 15 liters (Sphere Association, 2018). 
is vital, and can often make the difference whether children attend classes or not, especially for those from vulnerable groups. Schools and recreation areas should be relatively centrally located, cleared of surrounding thick bush and at a safe distance from roads used for heavy traffic or areas of the camp, to uphold and protect the safety of students (IOM, NRC \& UNHCR, 2015).

One school, one distribution centre and one health clinic need to be built for each sector $(5,000$ people). One health centre, one market, one feeding centre and one cemetery are to be provided per camp for 20,000 people. A hospital may be required for ten camps, 200,000 people (UNHCR, 2007). Fence and security services are always and issue of discussion and possible disagreement, but they may be advisable in certain settings.

Some specialized services are many times forgotten. Child protection and child care services, especially for children with disabilities, unaccompanied and separated children. Special protection must be extended to single women, single mothers, victims of abuse and victims of trafficking. The service of nutritional feeding centres is of great importance for lactating women, women with young children, malnourished children (supplementary and therapeutic feeding). Psychological, psycho-social and religious services contribute to the mental and spiritual well-being and the dignity of those living in the camp. The elderly, the sick ones and persons with disabilities also require special attention. 
Figure 10: An Ideal Layout

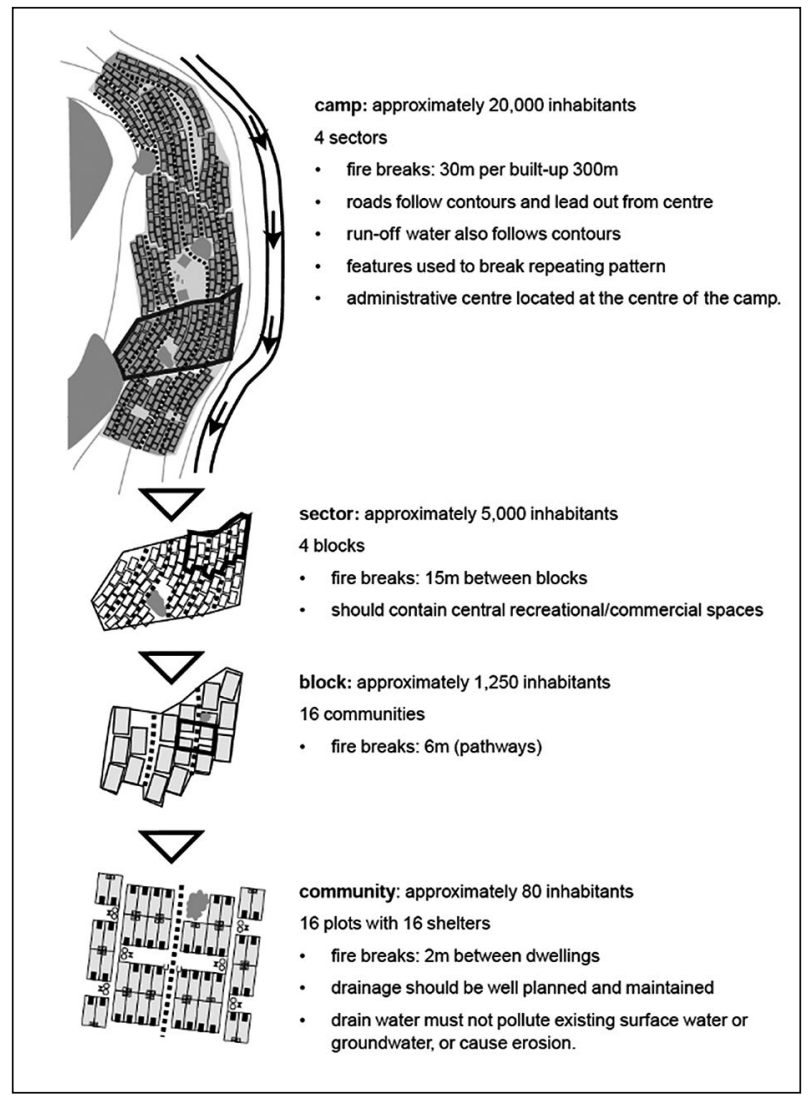

Note: Corsellis, Tom \& Vitale, Antonella: Transitional Settlement: Displaced Populations.

\section{Camps: Advantages and Disadvantages}

What are the main advantages of camps, in comparison especially to local dispersion?

Camps serve large population in a centralized and efficient way, where beneficiaries are easier to identify. The identification, registration, profiling and verification of the refugees / IDPs is indispensable for the management of the camp, and it is an important protection activity in itself. It is easier to provide protection to those living in the camps, and at the same time it is easier to secure the safety of the outside host community. The dignity of beneficiaries is more upheld when camps and services are well-organized and well-managed. 
Vulnerable groups (women, children, the elderly, people with disabilities, victims of abuse, separated children), who are most of the time forgotten and so many times victims of abuse, are more protected and better served. Beneficiaries are easier to communicate with, information flow and feed-back are faster and more efficient. It is also easier for advocacy purposes, for the benefit of the beneficiaries and also for the host community. Camps are more economic, since services are easier to be provided at a relatively lower cost, than in local dispersion.

The durable solutions are easier to organize from a camp setting than from a local dispersion setting. For refugees, durable solutions are

- voluntary repatriation to their home country after their safety can be guaranteed and they would not be persecuted anymore,

- local integration in the hosting community, and

- relocation / resettlement to a third country providing them a new home.

'For internally displaced persons, a durable solution is achieved when internally displaced persons no longer have any specific assistance and protection needs that are linked to their displacement and can enjoy their human rights without discrimination.' Durable solutions for internally displaced persons:

- return: sustainable reintegration at the place of origin,

- local integration: sustainable local integration in areas where internally displaced persons take refuge,

- resettlement: sustainable integration in another part of the country (IOM, 2019a).

Disadvantages of camps have been experienced in the humanitarian work for several decades, not only in the 2015 European migration wave. One of the most important disadvantages of camps is that it may create a population dependent on aid with little chance of work or autonomy. Dependency on external support is a dangerous factor especially if work and economic opportunities are not possible or not provided. There is an increased health risk if the camp is crowded, as larger populations live in a smaller area, and if the health and sanitation facilities and services are not sufficient and appropriate. Possible conflicts with the outside community may rise, especially if those living in the camps are provided more support and opportunities than the host community, if the camp beneficiaries pose a security threat to the host community or the possible environmental damage, due to deforestation or pollution to water sources for example, upsets the host community. The camp may be misused by those excluded from refugee status or by criminal elements for recruiting child soldiers, rape, abuse, 
smuggling, human trafficking. Finally, a larger population is more difficult to protect, thus special protection measures are advisable, however, attention needs to be paid that those protecting shall not abuse their power.

Figure 11: The Conflict between the Hosted Population and the Hosting Communities is an unfortunate Adverse Effect, especially in the Global South

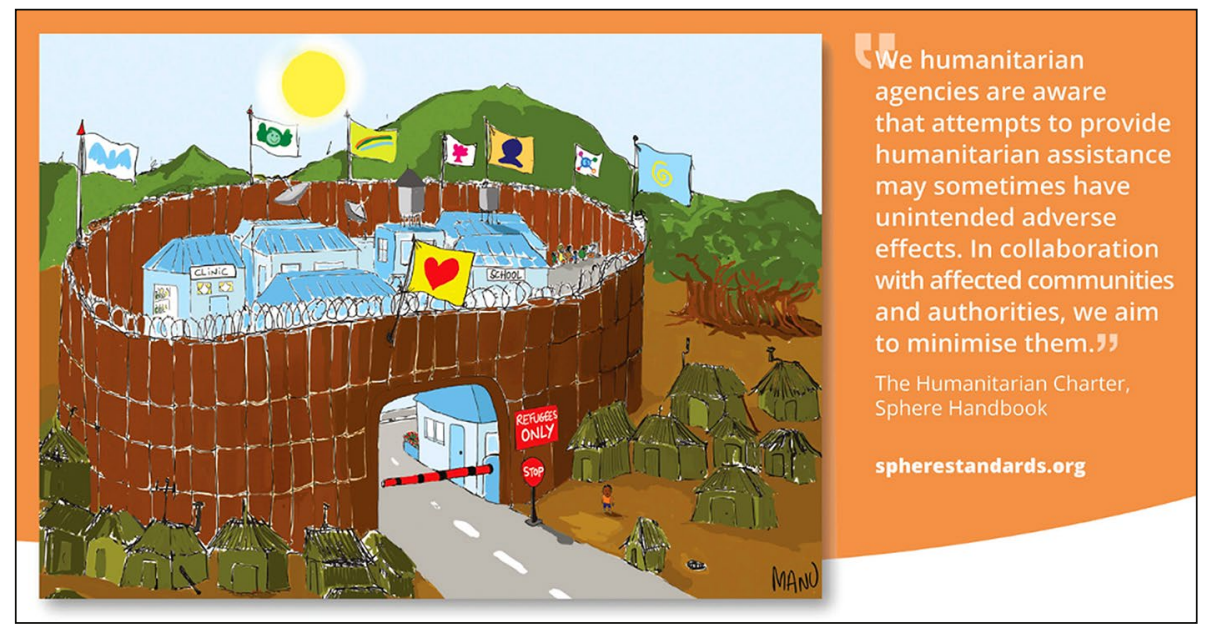

Note: Sphere: Cartoons Campaign Posters.

\section{Conclusion}

'Protecting people's safety and dignity is a primary aim to humanitarian action', underlines the UN publication that synthetises the findings, declarations and the outcome of the consultations leading up to the World Humanitarian Summit 2016. The ability to live in dignity, free from fear and violence is of great importance for people affected by crises. They pursue not only material assistance, but they want safety, dignity and hope (World Humanitarian Summit secretariat, 2015).

Migration can save the lives and/or improve the status of migrants and their families by escaping from persecution and violence, by improving socioeconomic status, by offering better education opportunities, and by increasing the income through remittances for 'left behind' family members. However, the migration process can also expose migrants to violence, risks, such as dangerous journeys, psychosocial stressors, sexual and physical abuses, nutritional deficiencies and changes in life-style, exposure to infectious diseases, limited access to protection, quality education and health care, interrupted care, smuggling, human trafficking, and crime (IOM, 2017). 
Camps can be a tool for upholding the dignity of those in the camp whether they are refugees, internally displaced persons or different kinds of migrants, and at the same time, camps can provide the safety and security for both, the hosted population and the hosting community.

The location and accessibility of shelters, buildings and facilities, the night lighting, distance to the toilet and bathing area from the shelter, and passive surveillance through visual lines are all of great importance in protection and provision of safety. Buildings used as collective centres must have alternative escape routes (Sphere Association, 2018). A well-designed camp protects the environment, disease outbreak and fires are prevented. Food, water, medical care and other services are in a walking distance for the displaced population. In order not to expose girls and women to danger, water points and latrines must be well-lit and close to homes (URL2).

Well-planned and well-organized camps do not only provide assistance and ensure the dignity to those displaced, help the effective and safe work of the aid workers, but can also contribute to reducing vulnerabilities, crime and gender-based violence, furthermore decrease security threats and risks.

\section{References}

Besenyő, J. (2010). Saharawi refugees in Algeria. AARMS, 9(1), 67-78.

Connor, P. (2016). Number of Refugees to Europe Surges to Record 1.3 Million in 2015. Pew Research Center Global Attitudes \& Trends. www.pewresearch.org/global/2016/08/02/number-of-refugees-to-europe-surges-to-record-1-3-million-in-2015/

Corsellis, T. \& Vitale, A. (2005). Transitional Settlement: Displaced Populations. Oxfam.

Inter-Agency Standing Committee (2015). Introduction to Humanitarian Action. A Brief Guide for Resident Coordinators. https://interagencystandingcommittee.org/system/files/rc_guide_31_ october_2015_webversion_final.pdf

International Organization for Migration IOM (2017). Migration Health in the Sustainable Development Goals: 'Leave No One Behind' in an increasingly mobile society. https://www.iom. int/sites/default/files/our_work/DMM/Migration-Health/Migration-in-the-Sustainable-development-goals.pdf

International Organization for Migration IOM (2019a). Glossary on Migration. International Migration Law No. 34. https://publications.iom.int/system/files/pdf/iml_34_glossary.pdf

International Organization for Migration IOM (2019b). World Migration Report 2020. International Organization for Migration. Geneva. https://publications.iom.int/system/files/pdf/ wmr_2020.pdf 
International Organization for Migration (IOM), Norwegian Refugee Council (NRC) \& UN Refugee Agency (UNHCR). (2015). Camp Management Toolkit. Edition June 2015. https:// www.refworld.org/pdfid/526f6cde4.pdf

Sphere Association (2018). Sphere Handbook: Humanitarian Charter and Minimum Standards in Humanitarian Response. Sphere Association.

UNHCR (2004). Protracted Refugee Situations. UNHCR internal document. Executive Committee of the High Commissioner's Programme, 30th Meeting. UN Doc. EC/54/SC/CRP.14. https://www.refworld.org/pdfid/4a54bc00d.pdf

UNHCR (2007). Handbook for Emergencies.

UNHCR (2010). Convention and Protocol Relating to the Status of Refugees. Text of the 1951 Convention Relating to the Status of Refugees. Text of the 1967 Protocol Relating to the Status of Refugees. https://www.unhcr.org/3b66c2aa10

UNHCR (2018). Global Trends Forced Displacement in 2017. UNHCR. https://www.unhcr.org/ statistics/unhcrstats/5b27be547/unhcr-global-trends-2017.html

UNHCR (2019). Global Trends Forced Displacement in 2018. https://www.unhcr.org/5d08d7ee7. pdf

UNHCR (2020b). Global Report 2019. UNHCR. Geneva. https://reporting.unhcr.org/sites/default/files/gr2019/pdf/GR2019_English_Full_lowres.pdf

UNHCR (2020c). Global Trends Forced Displacement in 2019. UNHCR. https://www.unher. org/5ee200e37.pdf

United Nations Economic and Social Council (1998). Guiding Principles on Internal Displacement. E/CN.4/1998/53/Add.2. https://undocs.org/E/CN.4/1998/53/Add.2

United Nations Office for the Coordination of Humanitarian Affairs OCHA, Department for International Development DFID \& Shelter Centre GSC (2010). Shelter after Disaster. Strategies for Transitional Settlement and Reconstruction. https://www.humanitarianlibrary.org/ sites/default/files/2014/01/shelterafterdisasterguidelines2010_0.pdf

World Humanitarian Summit secretariat (2015). Restoring Humanity: Synthesis of the Consultation Process for the World Humanitarian Summit. United Nations. https://reliefweb.int/sites/ reliefweb.int/files/resources/Restoring\%20Humanity-\%20Synthesis $\% 20$ of $\% 20$ the $\% 20$ Consultation $\% 20$ Process $\% 20$ for $\% 20$ the $\% 20$ World $\% 20$ Humanitarian $\% 20$ Summit.pdf

\section{Online links in this article}

URL1: Guterres, A. (2014). Opening Remarks at the 65th Session of the Executive Committee of the High Commissioner's Programme. António Guterres, United Nations High Commissioner for Refugees, Geneva, 30 September 2014. UNHCR. https://www.unhcr.org/afr/admin/ hcspeeches/542a6e6e9/opening-remarks-65th-session-executive-committee-high-commissioners-programme.html 
URL2: Shelter. UNHCR. https://www.unhcr.org/shelter.html

URL3: Lagerquist, J. (2017). 'Soaked': Harvey's victims find relief inside Houston's largest evacuation centre. CTV News. https://www.ctvnews.ca/world/soaked-harvey-s-victims-find-relief-inside-houston-s-largest-evacuation-centre-1.3567870?cache=yesclipId104062

URL4: Razon, J. (2020). Evac Center. Philippine News Agency. https://www.pna.gov.ph/photos/42567

URL5: Lim, W. M. (2018). The Turkish Pivot. Defense Politics Asia. https://defensepoliticsasia. com/the-turkish-pivot/

URL6: What is the Cluster Approach? UN OCHA. Humanitarian Response. https://www.humanitarianresponse.info/en/about-clusters/what-is-the-cluster-approach

URL7: UNHCR United States. (2016). Average length of stay in a \#refugee camp once it passes 5 years gets up to around 20 yrs now. Twitter. https://twitter.com/unhcrusa/status/732579811927941120

URL8: McClelland, M. (2014). How to Build a Perfect Refugee Camp. New York Times. https:// www.nytimes.com/2014/02/16/magazine/how-to-build-a-perfect-refugee-camp.html

URL9: McKnight, J. (2016). Architects for Society designs low-cost hexagonal shelters for refugees. Dezeen. https://www.dezeen.com/2016/04/14/architects-for-society-low-cost-hexagonal-shelter-housing-refugees-crisis-humanitarian-architecture/

URL10: Block, I. (2019). Refugee shelters could be built from concrete fabric in 24 hours. Dezeen. https://www.dezeen.com/2019/09/17/cortex-shelter-cutwork-refugee-architecture/

URL11: UNHCR. (2020a). Dadaab Refugee Complex. https://www.unhcr.org/ke/dadaab-refugee-complex

\section{Reference of the article according to APA regulation}

Szilágyi, B. (2021). Refugee Camp: A Tool for Dignity and Security. Belügyi Szemle, 69(SI4), 31-52. https://doi.org/10.38146/BSZ.SPEC.2021.4.3 